The Journal of

Mathematics and Computer Science

Available online at

http://www.TJMCS.com

The Journal of Mathematics and Computer Science Vol .5 No.3 (2012) 219 - 228

\title{
The Bankruptcy Prediction in Tehran share holding using Neural Network and it's Comparison with Logistic Regression
}

\author{
1Mahnaz Bagheri \\ Department of Mathematic, Islamic Azad University, Behshahr branch, Iran \\ m.bagheri@iaubs.ac.ir \\ Mehrdad Valipour \\ Department of Accounting, Islamic Azad University, Neka branch, Iran \\ valipour@iauneka.ac.ir \\ Vahid Amin \\ Department of Accounting, Payamnour University, Behshahr Branch \\ vahid_amin_ac85@yahoo.com
}

Received: May 2012, Revised: August 2012

Online Publication: December 2012

\begin{abstract}
The use of financial ratios for predicting companies' bankruptcy has always been considered by universities and economical institutions especially banks and other financial organizations. In such studies, statistical models like multiple distinctive analyses (MDA), logit Analysis, probit Analysis have usually been used. In this study, the prediction of accepted productive companies' bankruptcy in Tehran negotiable papers exchange has been paid by the use of artificial neural network (ANN) model and we have also made a comprehensive review on the models of bankruptcy prediction. In this study, artificial neural network model with logistic regression (LR) statistical model that is a useful statistical model in bankruptcy prediction has been compared. Our findings from these models on the basis of 80 companies' data showed that artificial neural network model has more accuracy than logistic regression statistical model in bankruptcy prediction.
\end{abstract}


Keywords: Bankruptcy prediction; financial ratios; Logistic Regression (LR); Artificial Neural Network (ANN).

\section{Intrudaction}

The rapid development of technology and its effect on the world of business along with extensive environmental changes have given growing momentum to economy, so that competitive approach of economical enterprises in the field of achievement to benefit has been limited and the possibility of bankruptcy and company's financial risk have been increased on the other hand, decision making in financial issues is always accompanied with risk because of future uncertainties. Thus, one way of helping to investors is prediction patterns offer about overall perspective and company's future role.

If these predictions are closer to reality, then decisions on the basis of such predictions will be more accurate.

One point that can help decision making process is the existence of suitable tools and models for evaluating financial relations and organization situation, because if unit decision maker doesn't have a suitable evaluation from organization, his/her choice will not be optimal. A tool which is used in the decision making about company is the models of bankruptcy prediction, so that it can help to suitable exploitation of investment opportunities and also prevention of wasting resources. Knowledge of bankruptcy prediction has a vital importance for all users of financial and has an effect on the decisions of decision maker groups.

First, one can make companies aware of bankruptcy occurrence by presentation of necessary warnings so that, they can do necessary measures with respect to these warnings, secondly, investors can discriminate desirable opportunities of investment from undesirable ones and they can invest their resources in suitable opportunities. Closer prediction of bankruptcy makes it easy for users that [1]. Bankruptcy is almost an ancient category and is basically a static system [2]. Bankruptcy means inadequacy of cash and inability to pay debts and current liabilities.

The purpose of this study is economical bankruptcy and with article 141 of the commercial law. Bankruptcy occurs when at least half of company's capital has been wasted due to incurred damages. So, the company will be subject to article 141 of commercial law and will be introduced bankrupt [3]. At first, William Beaver [4] used invariable analysis for examination of financial ratios power in financial insolvency prediction. He utilized mostly from ratios that were related to cash details in this analysis. Edward 
Altman [5] examined the effect of different combinations of financial ratios for predicting company's bankruptcy for the first time. Altman used multi distinctive analysis in his study. Shah and Murtaza [6] presented a model using ANN for bankruptcy prediction.

In this study, the information of 60 bankrupt companies and 54 solvent companies has been used within 1992 to 1994. The prediction accuracy of this model was 73 percent. Yim and Mitchell [7] have examined an index of 100 companies that included 20 bankrupt companies during the 1995 to 1999 in Australia. Two combinatory models of ANN-Plogit and ANN-PDA have been selected as the best models for bankruptcy prediction and their correct classification percentage was 91 percent for sound and insolvent companies. Another study has been done by Yim and Mitchell in Japan. They divided their Japanese sample into two groups of banks and companies.

The best combinatory model of neural networks was ANN-Logit-Plogit that could accurately classify $94 \%$ and $96 \%$ from the whole of insolvent and sound banks in this sample respectively and also $100 \%$ and $94.7 \%$ from insolvent and sound companies out of this sample. Reza Raei and Said Fallahpour [8] have presented a model for prediction of company's bankruptcy by the use of artificial neural networks. This model compared with multiple distinctive analysis (MDA) and its findings show that the percentage of bankruptcy prediction of neural networks model for the years of bankruptcy, one and two years before bankruptcy was $95.31 \%$, $88.12 \%$ and $78.12 \%$ respectively and also $93.44 \%, 86.56 \%$ and $71.25 \%$ for multiple distinctive analysis (MPA) model.

Edwards, Hairong, Chan and manger [9] have studied Australian companies. Financial information of 46 companies has been used in this study from 1988 to 1990. This included 23 financial insolvent companies and 23 sound companies. Artificial neural networks model was compared with logistic regression models and also step by step distinctive analysis with decision making tree model. The findings of this study show that the artificial neural networks model had better performance in comparison with other models. Multi layer preceptor on network has been used in over 80 percent of these studies.

Also, in few studies about bankruptcy prediction by Genetic programming (GP), Finding shows it's superiority to other statistical models [10]. With respect to above mentioned cases of this study, the following assumption can be taken with the purpose of bankruptcy prediction of accepted companies in Tehran negotiable papers exchange by the use of artificial neural network. 
General accuracy of artificial neural networks model in company's bankruptcy prediction is more than logistic regression model. For testability acceptance this research hypothesis has been changed into three statistical hypotheses for each year of $t, t-1$ and $t-2$. The $t$ year for bankrupt companies is the year that company has been subjected to article [4] of the commercial law and for solvent companies is the basis year of information gathering. It should be noted that the test of this hypothesis will be done in meaningful level of $0.05 \%$.

\section{Research Method}

Research method was descriptive with the approach of post-eventual. Historical information of companies has comparatively been studied for research hypothesis test. Two different statistical populations have been studied in this research; the first one is accepted productive companies in Tehran negotiable paper exchange markets that have been bankrupt (companies subject to article [4] of the commercial law.)

This population includes 44 companies that of course there was not complete access to the information of 4 companies, and the sample of bankrupt companies has been chosen from it. The second statistical population includes accepted solvent companies in Tehran negotiable papers exchange market. This population includes 332 companies, so that the sample of solvent companies has been chosen from it.

Furthermore, the examination of research literature shows that coupling sampling has been used in most of the previous studies and for this reason we have used such method in this research.

So, the sample used in this research includes 40 bankrupt companies (chosen from bankrupt companies population) so that all bankrupt companies are available and also 40 solvent companies (chosen from solvent companies population with respect to selected samples of bankrupt companies population) that have been chosen randomly from it's population. Data gathering has been done through referring to three-year old financial statements available in the library of Tehran negotiable papers exchange. 
In this study, the original sample has been divided into four parts of 20's. There are 10 bankrupt companies and 10 sound or solvent companies in each of them. Then, four subsamples have been formed by the use of this 20 's samples, so that, in each subsample, we have used 60 samples for network training (in the case of LR, model drawing) and 20 samples for network testing (in the case of LR, model testing).thus, we have replaced 20 samples of training set with 20 samples of tentative set in each subsample.

Chart 1.result of average equality test about variables used in the year $t$

\begin{tabular}{|c|c|c|c|c|}
\hline Sig & Variable $\mathrm{t}$ & $\begin{array}{c}\text { The average } \\
\text { in Bankrupt } \\
\text { companies }\end{array}$ & $\begin{array}{c}\text { The } \\
\text { average } \\
\text { in Non- } \\
\text { Bankrupt } \\
\text { companies }\end{array}$ & Variables \\
\hline $0 / 000$ & $-10 / 043$ & - 0/0488 & 0/1571 & $\begin{array}{r}\text { Ratio of Earnings before Interest and } \\
\text { Tax to Total Assets( EBIT_TA) }\end{array}$ \\
\hline $0 / 014$ & $-1 / 460$ & $-0 / 0797$ & 0/7397 & $\begin{array}{r}\text { Ratio of Earnings before Interest and } \\
\text { Tax to Net Sales (EBIT_NS) }\end{array}$ \\
\hline $0 / 000$ & $-4 / 990$ & $0 / 0562$ & $0 / 6423$ & $\begin{array}{l}\text { Ratio of Total Equity to total Liabilities( } \\
\text { TE_TD }\end{array}$ \\
\hline $0 / 000$ & $-4 / 763$ & $-0 / 1317$ & 0/0978 & $\begin{array}{l}\text { Ratio of Working capital to total assets ( } \\
\text { WC_TA }\end{array}$ \\
\hline $0 / 000$ & $-5 / 015$ & $0 / 8616$ & $1 / 2271$ & $\begin{array}{r}\text { Ratio of Current Assets to Current } \\
\text { Liabilities ( CA_CL) }\end{array}$ \\
\hline
\end{tabular}

All variables used in which is the research literature have been examined to determine independent variables so, first we calculate statistics of each variable in each two groups and also equality test of averages has been done. In this stage, final decision for choosing five original variables has been done. Table 1 shows the results of equality test of averages for applied variables. To summarize data, we have first calculated ratios by the use of gathered data for all companies and for each years of t, t-1 and t-2. All actions related to summarization have been done by MS Excel software. After data summarization, we have first considered the statistical model, i.e. logistic regression (LR) .This model has been obtained by the use of logistic regression available in SPSS software.

In the next step, bankruptcy prediction will be done by the use of Artificial Neural Networks through MATLAB software and by tool box Neural Network.

\section{Artificial Neural Network and Logistic Regression}

Artificial neural network is a type of information process pattern that is pried from inherent or natural neural systems. Artificial neural networks are dynamic systems that can transfer hidden rules and knowledge data 
into network structure. Through experimental data processing, this is called intelligent system [11].

Neural networks are composed of a series of layers that include simple parts of processor called neuron and they can act in parallel. Each input layer is related to one or more middle layer and also middle layers are connected to output layer [12]. Since many factors like hidden layers, the numbers of hidden layers neurons, data normalization and learning algorithm have an effect on neural networks function, so, the best architecture of neural network will be obtained through experiment try and error [13]. Error back propagation network (BP) that is a type of feed forward network transformation function used in this study, is a sigmoid function that its formula is equal to: $\mathrm{f}($ net $)=\left(1+\mathrm{e}^{- \text {net }}\right)^{-1}$. Net means: the total weight of input variable from previous layer. By this function, the output variable amount will be between zero and one. Performance function for network training is considered as the mean sum of squared errors (MSE) that is: $\mathrm{F}=\mathrm{MSE}=\frac{1}{\mathrm{n}} \sum_{\mathrm{i}=1}^{\mathrm{n}}\left(\mathrm{e}_{\mathrm{i}}\right)^{2}$. The other information related to artificial neural network are: the number of hidden layer $=1$, the number of hidden layer neurons $=10$, learning rate $=0.5$.the iteration number depends on learning rate related to performance function. So, with 0.5 learning rate the number of iterations in neural network 1 to 4 in the year $t$ will be 132, 185, 135 and 156 respectively.

In this study, bankrupt companies are introduced as number zero and solvent companies as number one. So, output result of this network should be like this. Since network output is a number between zero and one through sigmoid transformation function, so, if numerical output is less than 0.5 , it will be classified as a solvent company.

Logistic regression is a robust statistical model that is like normal regression, but with this difference that the method to estimate the coefficients is not similar. In logistic regression, instead of minimizing squared errors (that will be done in normal regression). The probability of an event occurrence will be maximized. A concept called odds ratio (ratio of $\frac{P_{i}}{1-P_{i}}$ that is ratio of event happening probability to no event happening probability) has been used in logistic regression. Odd ratio logarithm will be calculated on the basis of $\ln \left(\frac{P_{i}}{1-P_{i}}\right)=\beta_{0}+\beta_{i} x_{i}$.This model called logic model [14]. 


\section{Research findings}

In this section, we will present research findings and their analysis in the order of scenario. Chart 2 shows prediction total results of four subsamples of artificial neural network model (ANN) along with logistic regression model (LR) for the year $t$.

Chart 2.Prediction results for the year $\mathrm{t}$

\begin{tabular}{|c|c|c|c|c|c|c|c|c|c|}
\hline & \multirow{2}{*}{$(\mathrm{t})$} & \multicolumn{4}{|c|}{ Artificial Neural Network } & \multicolumn{4}{|c|}{ Logistic Regression } \\
\hline & & (1) & (2) & (3) & (4) & (1) & (2) & (3) & (4) \\
\hline \multirow{6}{*}{ Total } & \multirow{2}{*}{ Bankrupt } & 37 & 39 & 39 & 39 & 37 & 36 & 37 & 37 \\
\hline & & $\% 99 / 50$ & $\% 97 / 50$ & $\% 97 / 50$ & $\% 97 / 50$ & $\% 92 / 50$ & $\% 90$ & $\% 92 / 50$ & $\% 92 / 50$ \\
\hline & \multirow{2}{*}{$\begin{array}{c}\text { Non- } \\
\text { bankrupt }\end{array}$} & 39 & 39 & 39 & 38 & 37 & 38 & 37 & 38 \\
\hline & & $\% 97 / 50$ & $\% 97 / 50$ & $\% 97 / 50$ & $\% 95$ & $\% 92 / 50$ & $\% 95$ & $\% 92 / 50$ & $\% 95$ \\
\hline & \multirow{2}{*}{ Total } & 76 & 78 & 78 & 77 & 74 & 74 & 74 & 75 \\
\hline & & $\% 95$ & $\% 97 / 50$ & $\% 97 / 50$ & $\% 96 / 25$ & $\% 92 / 50$ & $\% 92 / 50$ & $\% 92 / 50$ & $\% 93 / 75$ \\
\hline
\end{tabular}

These results show that prediction accuracy of ANN is more than LR in all four subsamples. The difference of these two models in subsample (1), (2), (3) and (4) is equal to $2.5 \%, 5 \%$, and $2.5 \%$ respectively. The results of coupling comparison test for the year $\mathrm{t}$ is shown in chart 3 .

Chart3. The result of coupling comparison test for the year $t$

\begin{tabular}{|c|c|c|c|c|c|c|c|c|c|}
\hline & & \multicolumn{5}{|c|}{ Paired Differences } & \multirow[b]{3}{*}{$\mathrm{T}$} & \multirow[b]{3}{*}{ df } & \multirow{3}{*}{$\begin{array}{l}\text { Sig. } \\
(2- \\
\text { tailed })\end{array}$} \\
\hline & & \multirow[b]{2}{*}{ Mean } & \multirow{2}{*}{$\begin{array}{c}\text { Std. } \\
\text { Deviation }\end{array}$} & \multirow{2}{*}{$\begin{array}{c}\text { Std. Error } \\
\text { Mean }\end{array}$} & \multicolumn{2}{|c|}{$\begin{array}{l}95 \% \text { Confidence Interval of } \\
\text { the Difference }\end{array}$} & & & \\
\hline & & & & & Lower & Upper & & & \\
\hline Pair 1 & ANN - LR & 3.75000 & 1.44338 & .72169 & 1.45327 & 6.04673 & 5.196 & 3 & .014 \\
\hline
\end{tabular}

Chart 4 shows the prediction total results of four subsamples of ANN model along with LR model for the year $\mathrm{t}-1$. These findings show that prediction accuracy of ANN is more than LR in all four subsamples. The difference of these two models in subsamples 1 to 4 is equal to $6.25 \%, 7.5 \%, 3.75 \%$ and $5 \%$ respectively. The results of coupling comparison test for the year t- 1 is shown in chart 5. 
M. Bagheri, M. Valipour, V. Amin/ TJMCS Vol .5 No.3 (2012) 219 - 228

Chart 4.prediction result for the year t-1

\begin{tabular}{|c|c|c|c|c|c|c|c|c|c|}
\hline \multirow{2}{*}{\multicolumn{2}{|c|}{$(\mathrm{t}-1)$}} & \multicolumn{4}{|c|}{ Artificial Neural Network } & \multicolumn{4}{|c|}{ Logistic Regression } \\
\hline & & $(1)$ & $(2)$ & (3) & $(4)$ & $(1)$ & $(2)$ & (3) & $(4)$ \\
\hline \multirow{6}{*}{ Total } & \multirow{2}{*}{ Bankrupt } & 35 & 36 & 35 & 35 & 34 & 34 & 34 & 34 \\
\hline & & $\% 87 / 50$ & $\% 90$ & $\% 87 / 50$ & $\% 87 / 50$ & $\% 85$ & $\% 85$ & $\% 85$ & $\% 85$ \\
\hline & \multirow{2}{*}{$\begin{array}{c}\text { Non- } \\
\text { bankrupt }\end{array}$} & 35 & 36 & 34 & 36 & 31 & 32 & 32 & 33 \\
\hline & & $\% 87 / 50$ & $\% 90$ & $\% 85$ & $\% 90$ & $\% 77 / 50$ & $\% 80$ & $\% 80$ & $\% 82 / 50$ \\
\hline & \multirow{2}{*}{ Total } & 70 & 72 & 69 & 71 & 65 & 65 & 66 & 67 \\
\hline & & $\% 87 / 50$ & $\% 90$ & $\% 86 / 25$ & $\% 88 / 75$ & $\% 81 / 25$ & $\% 82 / 50$ & $\% 82 / 50$ & $\% 88 / 75$ \\
\hline
\end{tabular}

Chart 5.the result of coupling comparison test for the year t-1

\begin{tabular}{|c|c|c|c|c|c|c|c|c|c|}
\hline & & \multicolumn{5}{|c|}{ Paired Differences } & \multirow[b]{3}{*}{$\mathrm{T}$} & \multirow[b]{3}{*}{ Df } & \multirow{3}{*}{$\begin{array}{c}\text { Sig. } \\
(2- \\
\text { tailed) }\end{array}$} \\
\hline & & \multirow[b]{2}{*}{ Mean } & \multirow{2}{*}{$\begin{array}{c}\text { Std. } \\
\text { Deviation }\end{array}$} & \multirow{2}{*}{$\begin{array}{c}\text { Std. Error } \\
\text { Mean }\end{array}$} & \multicolumn{2}{|c|}{$\begin{array}{l}95 \% \text { Confidence Interval of } \\
\text { the Difference }\end{array}$} & & & \\
\hline & & & & & Lower & Upper & & & \\
\hline Pair 1 & ANN - LR & 5.62500 & 1.61374 & .80687 & 3.05717 & 8.19283 & 6.971 & 3 & .006 \\
\hline
\end{tabular}

Chart 6 shows the prediction total results of four subsamples of ANN which is more than LR in all four subsamples. The difference of these two models in subsamples 1 to 4 is equal to $7.50 \%, 10 \%, 7.50 \%$ and $10 \%$ respectively. The results of coupling comparison test for the year t- 2 is shown in chart 7.

Chart 6.prediction results for the year t-2

\begin{tabular}{|c|c|c|c|c|c|c|c|c|c|}
\hline & \multirow{2}{*}{$(\mathrm{t}-2)$} & \multicolumn{4}{|c|}{ Artificial Neural Network } & \multicolumn{4}{|c|}{ Logistic Regression } \\
\hline & & $(1)$ & $(2)$ & (3) & (4) & (1) & $(2)$ & $(3)$ & $(4)$ \\
\hline \multirow{6}{*}{ Total } & \multirow{2}{*}{ Bankrupt } & 35 & 36 & 32 & 34 & 30 & 31 & 32 & 32 \\
\hline & & $\% 75$ & $\% 90$ & $\% 80$ & $\% 85$ & $\% 75$ & $\% 77 / 50$ & $\% 80$ & $\% 80$ \\
\hline & \multirow{2}{*}{$\begin{array}{c}\text { Non- } \\
\text { bankrupt }\end{array}$} & 37 & 33 & 35 & 35 & 31 & 30 & 29 & 29 \\
\hline & & $\% 92 / 50$ & $\% 82 / 50$ & $\% 87 / 50$ & $\% 87 / 50$ & $\% 77 / 50$ & $\% 75$ & $\% 72 / 50$ & $\% 72 / 50$ \\
\hline & \multirow{2}{*}{ Total } & 67 & 69 & 67 & 69 & 61 & 61 & 61 & 61 \\
\hline & & $\% 83 / 75$ & $\% 86 / 25$ & $\% 83 / 75$ & $\% 86 / 25$ & $\% 76 / 25$ & $\% 76 / 25$ & $\% 76 / 25$ & $\% 76 / 25$ \\
\hline
\end{tabular}


M. Bagheri, M. Valipour, V. Amin/ TJMCS Vol .5 No.3 (2012) 219 - 228

Chart 7.the results of coupling comparison test for the year $\mathrm{t}-2$

\begin{tabular}{|c|c|c|c|c|c|c|c|c|c|}
\hline & & \multicolumn{5}{|c|}{ Paired Differences } & \multirow{3}{*}{$\mathrm{t}$} & \multirow{3}{*}{ Df } & \multirow{3}{*}{$\begin{array}{l}\text { Sig. (2- } \\
\text { tailed) }\end{array}$} \\
\hline & & \multirow{2}{*}{ Mean } & \multirow{2}{*}{$\begin{array}{c}\text { Std. } \\
\text { Deviation }\end{array}$} & \multirow{2}{*}{$\begin{array}{l}\text { Std. } \\
\text { Error } \\
\text { Mean }\end{array}$} & \multicolumn{2}{|c|}{$\begin{array}{l}95 \% \text { Confidence Interval of } \\
\text { the Difference }\end{array}$} & & & \\
\hline & & & & & Lower & Upper & & & \\
\hline Pair 1 & ANN - LR & 8.75000 & 1.44338 & .72169 & 6.45327 & 11.04673 & 12.124 & 3 & .001 \\
\hline
\end{tabular}

Our findings show that artificial neural network model (ANN) has a good power in prediction of company's bankruptcy. We can say this with high certainty. It is natural that the power of model prediction will be decreased by becoming farther from the year of bankruptcy occurrence. We can say that prediction total accuracy of artificial neural network model in bankruptcy prediction is meaningfully more than logistic regression model. Thus, the main research hypothesis of this study is accepted.

\section{Conclusion}

Findings about bankruptcy prediction through artificial neural network by MATLAB software and Neural Network Toolbox available show that prediction percentage in classifying companies for four subsamples in the year $\mathrm{t}$ are $95 \%, 97.50 \%, 97.50 \%$, and $96.25 \%$ respectively and for the year t- 1 are $87.50 \%, 90 \%, 86.25 \%$, and $88.75 \%$ respectively and also for the year t- 2 are $83.75 \%, 86.25 \%, 83.75 \%$, and $86.25 \%$ respectively. This model with the meaningful level of 5\% has more power in company's bankruptcy prediction in comparison with logistic regression model. Shah and murtaza, raei and fallah pour and also Edward et.al have shown in previous studies, that we can use artificial neural network with high certainly compared with statistical models.

\section{Acknowledgment}

This study was carried out by research budget of Islamic Azad University, Behshahr Branch.

\section{References}

[1] R. Raei, and S. Fallahpour, Corporate financial distress prediction using artificial neural networks, Journal of Financial Research, (2004),no 17, p 39. 
[2] M. Nwogugu, decision-making risk and corporate governance, a critique of mythological issues in bankruptcy / recovery prediction models, Applied Mathematics and computation 185 (2007)178-196

[3] J. Mansour, Commercial Law with Czech law Regulations, Didar Publication, (2009)

[4] W. H. Beaver, Financial ratios as predictors of failure. Journal of Accounting Research, Empirical Research in Accounting, Selected Studies, (1966), 71-111.

[5] E. I. Altman, Financial ratios discriminate analysis and the Prediction of corporate bankruptcy. The Journal of Finance, (1968), 23 (4), 589- 609

[6] J. R. Shah, M. B. Murtaza, A neural network based clustering procedure for bankruptcy Prediction. American Business Review, (2000),18 (2), 8086.

[7] H. Mitchell And J. Yim, A comparison of Australian Financial service failure models: Hybrid neural networks, logit models and discriminate analysis, working paper (November 2002).

[8] R. Raei, S. Fallahpour, Application of Support Vector Machine to predict financial distress of companies with use of financial ratios, Review of accounting and auditing,(2008), p 17-34.

[9] V. Edwards, H. Yu, P. Chan, G. Manger, Corporate Failure Prediction (Bankruptcy) in Australia - From Zeta to Neural Networks, Electronic copy available , (2009).

[10] H. Etemadi, A. A. Anvary Rostami, H. Farajzadeh Dehkordi, A Genetic Programming model for bankruptcy prediction: Empirical evidence from Iran, Expert system with Application 36 (2009)3199-3207.

[11] M. Ghazanfari, J. Erkat, Neural networks (principles and functions), Tehran, Publications with University of Science and Technology of Iran, (2004).

[12] M. Arab, M. Akbari, M. Shahmirzadi, Predicting corporate bankruptcy using neural networks, Journal of Accountant, (2008) , No 20, p $34-38$.

[13] A. Azar and Momeni, Mansouri, Statistics and its Application in Management (Statistical Analysis), Tehran, Publications Samt, (2007).

[14] H. Mitchell And J. Yim, A comparison of Japanese failure models: Hybrid neural networks, logit models, and discriminate analysis, International Journal of Asian Management, (2004), 103-120. 